\title{
Importance of taking Anamnesis in Dentistry and Assessment of Knowledge and Attitudes of Dental Students
}

\author{
${ }^{1}$ Beste Inceoglu, ${ }^{2}$ Elif Naz Yakar, ${ }^{3}$ Naile Cura, ${ }^{4}$ Hakan Eren, ${ }^{5}$ Sebahat Gorgun
}

\begin{abstract}
Aim: The medical history (anamnesis) of a patient is information gained by a physician by asking specific questions, either of the patient or of other people who know the person and can give suitable information. The purpose of the study is to describe the significance level of taking anamnesis among dentists and dentistry students.
\end{abstract}

Materials and methods: In our study, we designed a selfadministered anonymous questionnaire (Fig. 1) consisting of 26 questions which was addressed voluntarily to 332 (208 female, 124 male) students and dentists at the Ankara University, Faculty of Dentistry. Answers were evaluated statistically according to five-point scale. Data were analyzed using the statistical software package SPSS 15.0 (IBM, New York, NY).

Results: Significant differences were found between the responses of male and female participants for some of the questions. On the other hand, all participants knew about the relationship between the ethical-legal issues and taking systemic anamnesis. Results of the study show that participants are aware of the importance of malpractice lawsuits.

Conclusion: According to the results of our study, we found that dentist-patient relationship is strengthened with increasing experience. The ability to reflect on the encounter and learning from the experience is an important component in developing self-awareness and professionalism in dentistry.

Keywords: Medical history, Anamnesis, Dental education.

How to cite this article: Inceoglu B, Yakar EN, Cura N, Eren $\mathrm{H}$, Gorgun S. Importance of taking Anamnesis in Dentistry and Assessment of Knowledge and Attitudes of Dental Students. J Contemp Dent 2014;4(2):87-91.

Source of support: Nil

Conflict of interest: None

\section{INTRODUCTION}

The medical history (anamnesis) of a patient is that 'information obtained by a physician by asking specific questions; either of the patient or of other people who know the person and can give suitable information, with the aim of obtaining

\footnotetext{
${ }^{1,2}$ Research Assistant, ${ }^{3,4}$ Specialist, ${ }^{5}$ Professor

$1,2,4,5$ Department of Dentomaxillofacial Radiology, Ankara University, Ankara, Turkey

${ }^{3}$ Department of Dentomaxillofacial Surgery, Ankara University Ankara, Turkey
}

Corresponding Author: Hakan Eren, Specialist, Department of Dentomaxillofacial Radiology, Ankara University, Ankara, Turkey Phone: 903122965634, e-mail: dthakaneren@yahoo.com.tr information useful in formulating a diagnosis and providing medical care to the patient'. ${ }^{1}$ Anamnesis varies in their dept and focus. Systemic, familiar, dental, present, sexual, social (occupation, drug use) are types of anamnesis. ${ }^{2}$

Taking a medical history in dentistry is an important tool in the detection of medical problems of patients. ${ }^{3}$ Assessment of the patient's general health before any dental approach is necessary to identify any systemic conditions, which may affect treatment procedure and allow the dentist to evaluate the risks and reduce possible complications. ${ }^{4}$ The purpose of dental treatment is to satisfy patient's needs. The success of the treatment is built upon careful medical anamnesis taken with a clinical examination for diagnosis of the problem that has been presented. Anamnesis is not only a wise approach to medical history but also, it is essential for the establishment of a successful dentist-patient relationship. If dentist cannot take a detailed anamnesis, an accurate diagnosis cannot be formulated and dental treatment may increase the risk of acute medical complications.

Patients are sometimes not satisfied with the treatment that performed by dentists. In most cases, such dissatisfaction can be resolved with mutual conversation of patient and dentist, but sometimes the patient resorts to a legally judicial authority where judge whether the complaint is reasonable and, if necessary, can take subsequent action against the dentist. ${ }^{5}$ General description of dental malpractice that is consistent among countries would be described as medical malpractice for an injury due to negligent dental work, failure to diagnose or treat possible precarious oral conditions, delayed diagnosis or treatment of oral disease or other precarious oral conditions, as well as any malevolent or otherwise intentional misconduct on the dental professional's part. ${ }^{6}$ Therefore, well-kept medical history is important for ethical and legal aspects in dentistry. Dentists always must avoid harm to the patient and establish a balance with the helpful principles. This situation is not just a legal responsibility, but also an ethical principle. The well-compatibility between dentists, patients and their relatives protects the dentist from possible difficulties. ${ }^{7,8}$

The purpose of this article is to describe the significance level of taking anamnesis among dentists and dentistry students and getting the knowledge, attitudes and behaviors, 
and to emphasize the importance of dental education with a specific questionnaire. Also findings were obtained whether there is difference between specialist dentists and undergraduate students.

\section{MATERIALS AND METHODS}

A self-administered anonymous questionnaire (Table 1) consisting of 26 questions was designed and addressed vol- untarily to 332 (208 female, 124 male) students and dentists at the Ankara University, Faculty of Dentistry. Two hundred sixty-nine of the students were undergraduate (UGS) and 63 of them were postgraduate (PGS). The UGS group was included 124 fourth year students (DS4) and 145 fifth year students (DS5). DS4 group was also surveyed after 1 year. Our aim was to collect the significance level of taking anamnesis among postgraduate and undergraduate dentistry

Table 1: The questionnaire that was used in the study

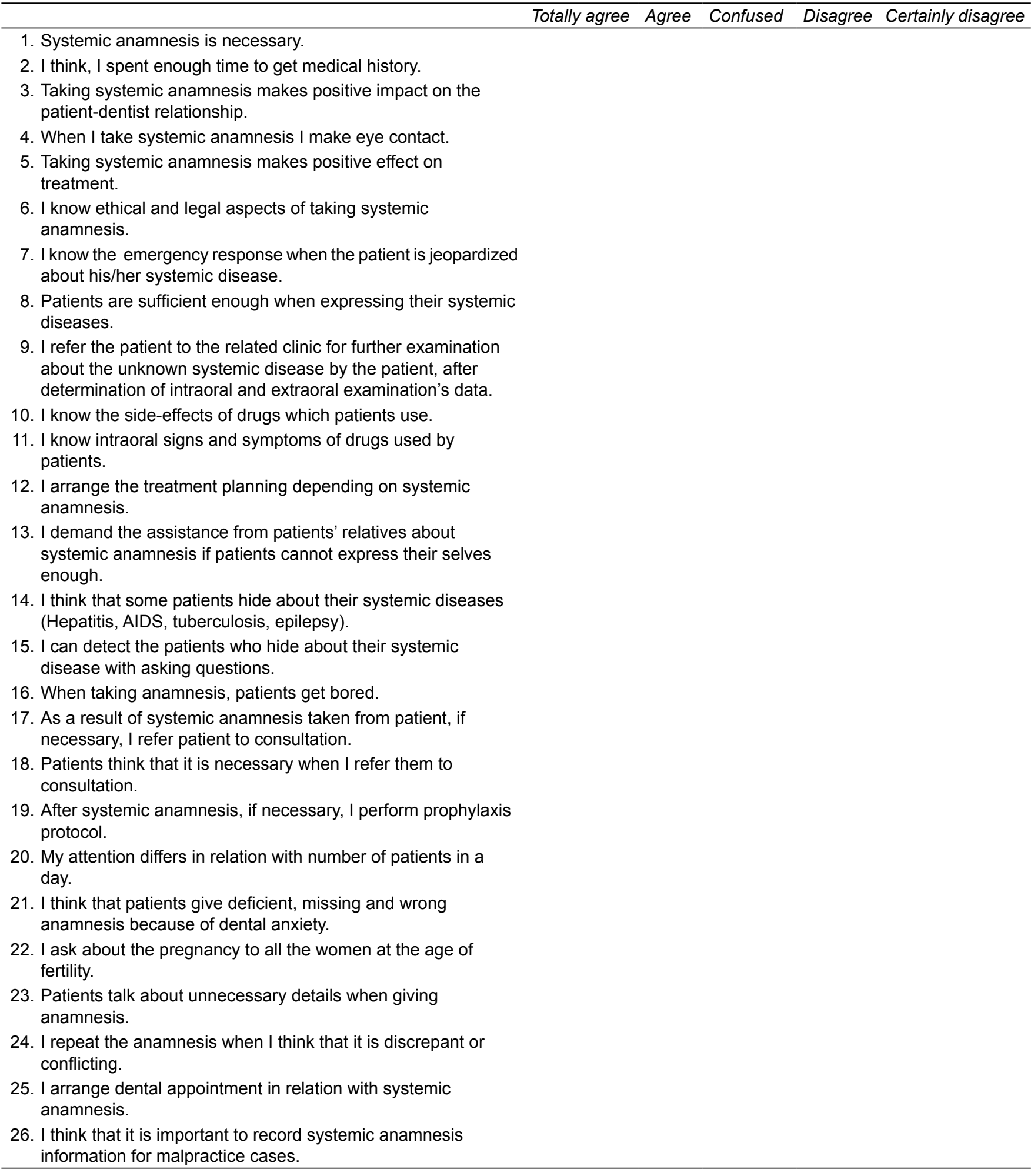


students and getting the knowledge, attitudes and behaviors, and to emphasize the importance of dental education with a specific questionnaire.

Written permission was taken from ethics committee of Ankara University, Faculty of Dentistry for applying the questionnaire. Answers were evaluated statistically according to five-point scale. Surveyed undergraduate students were 4 th and 5 th year intern dentists who were practicing in clinics of dentistry faculty under surveillance of proficient staff between October 2010 and July 2012. Data were analyzed using the statistical software package SPSS 15.0 (IBM, New York, USA). Differences between gender and other groups were evaluated using Chi-square test (significance level was set at $\mathrm{p} \leq 0.05$ ).

\section{RESULTS}

Significant differences were found between the responses of male and female participants for some of the questions (Graph 1). According to the results of question 7 which about the emergency response, males were found more experienced than females $(p<0.01)$. Furthermore, significant differences were found for question 12, 22 and 24. Question 12 was about treatment planning, question 22 was about pregnancy and question 24 was about the repeat of the anamnesis when conflicting. Female dentists were found more sensitive than male dentists $(\mathrm{p}<0.01)$. No statistically significant differences were found in other questions.

Statistically significant differences were found between the responses of DS4 and DS5 for the questions 1, 6, 7, 9, 10, 11, 15, 17, 19 (Graph 2). DS5 students were found more responsive than DS4 students. Same students became more sensitive over 1 year. Question 1 was about importance of systemic anamnesis, question 6 was about ethical and legal aspects, question 7 was about emergency response, question 9 was about related clinic examination to the

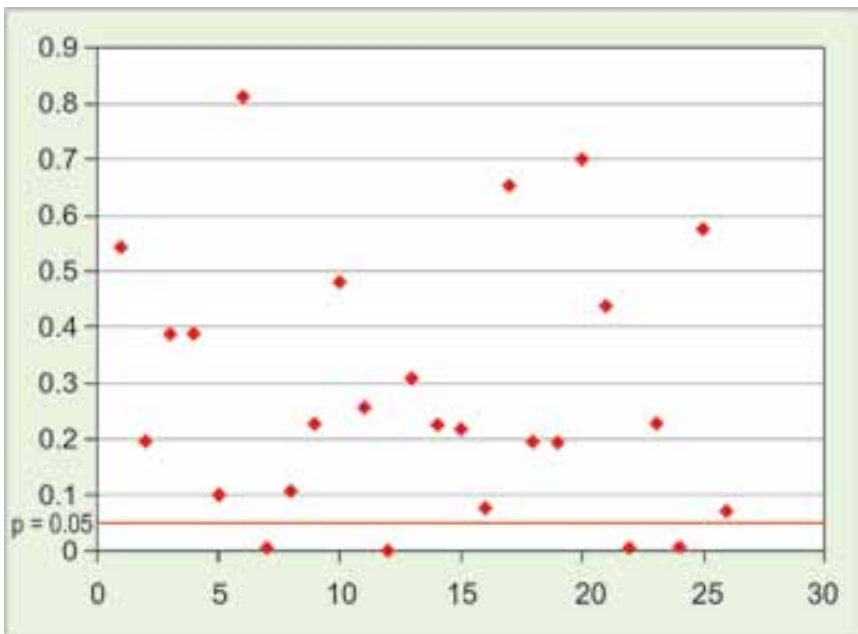

Graph 1: Statistical distribution of questionnaire according to gender of participants. Note: Answers above the red line are statistically significant unknown systemic disease of the patient; according to the answers of these questions, there were significant differences $(p<0.05)$. Also; answers of question 10 (side effects of drugs), question 11 (intraoral signs and symptoms of drugs), question 15 (detection of the patients' systemic disease which is hidden by patient), question 17 (consultation) and question 19 (prophylaxis protocol) showed statistically significant differences $(p<0.01)$. For answers of the other questions, no differences were found $(\mathrm{p}>0.05)$.

In comparison between groups of UGS and PGS's, there were statistically significant differences within nine questions (Graph 3). According to answers of questions 7, 9, 22; the significant differences were found between two groups. Answers of questions 11 and 19 showed that UGS were more sensitive than PGS $(\mathrm{p}<0.05)$. According to answers of questions 10,16 and 17; PGS were aware of side effects of drugs, taking anamnesis patients get bored and refer to consultation more than UGS $(\mathrm{p}<0.01)$.

\section{DISCUSSION}

Several studies assessed the dental practitioners' and students' knowledge about the importance of taking medical history in dental education and focused on behavior and attitudes of clinicians. In general, the results of the recent studies showed that participants were aware of the significance of taking medical history. Answers of questionnaire were in a satisfactory score. The relationship between dentist and patient is the first step of the dental treatment. If the first interaction results in serious miscommunications/ misinterpretations regarding the patient's understanding of the diagnosis, treatment options, and cost; the pretreatment duration with the patient provides reducing of the dentalstress and confidence to dentist. ${ }^{9,10}$ In our study, we established the volunteers place emphasis to allow time to their patients before treatment for more comfortable operation.

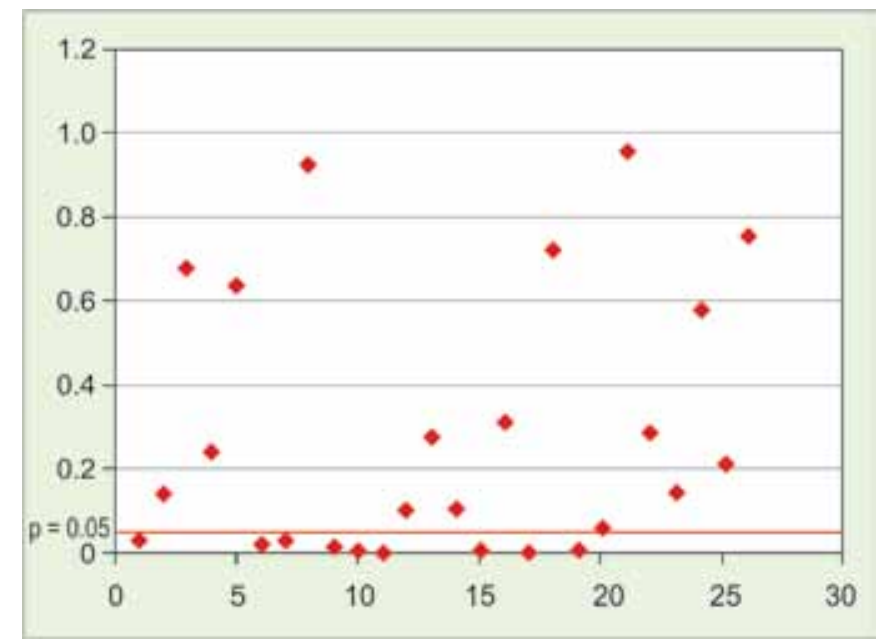

Graph 2: Statistical distribution of questionnaire according to comparison of DS4 and DS5 groups. Note: Answers above the red line are statistically significant 


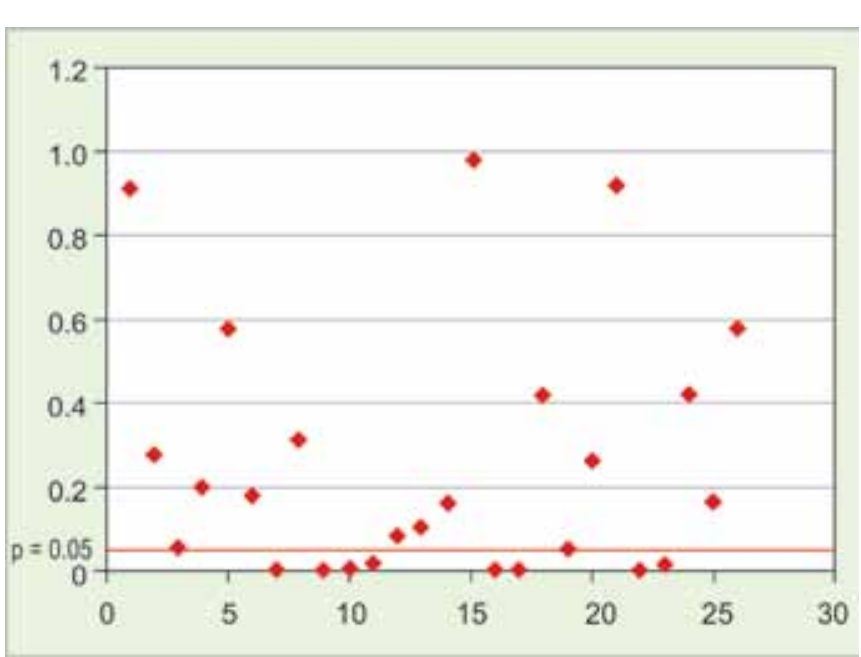

Graph 3: Statistical distribution of questionnaire according to comparison of UGS and PGS groups. Note: Answers above the red line are statistically significant

Additionally, the eye contact is also important for set dentist's trust in patient, so patient thinks more carefully listening to her/his complaints, by the way dentist-patient communication gets stronger.

Before dental treatment, dentist must learn all the medical problems that could be risk for both dentist and patient during treatment. On the other hand, selected questions can make a difference for reducing the risks. Dental practitioners, like all the other healthcare professionals, might engage with legal claims and can be sued if patients are not satisfied with the dental treatment. In our study, participants knew about the relationship between the ethical-legal issues and taking systemic anamnesis. Thus, results of the study show that participants are aware of the importance of malpractice lawsuits. Under today's developments in medical technology, there are a lot of treatment options for a single condition. Therefore, increases in treatment options give rise doctor to take more risks. Taking more risks can cause to failure of treatment or malpractice. Correspondingly, the patient and/or the relatives of the patient can go to court and sue the medical staff when they do not receive sufficient medical treatment or when they think they are harmed as a result of a faulty treatment intervention. As a result of that, the increased number of compensation cases brought against doctors in recent years has become a major concern for the medical industry not only in Turkey but also throughout the world. ${ }^{11,12}$

Patient's systemic conditions constituent his/her general health such hypertension, diabetes mellitus, asthma, allergy and epilepsy must be identified clearly in the first step. Otherwise, the treatment could be influenced and arise a situation that requires urgent intervention. In such emergency situations, dentists have a short period of time for the correct intervention. So, taking medical history prevents the dentist against potential risks. According to the results of survey, female dentists were more undecided about emergency inter- vention than male dentists. This result is probably associated with panic during emergency situation, so female dentists can be called nerveless. As a result, emergency action is not only based on the knowledge, but also it needs a calm practitioner. Female dentists' answers showed that their knowledge is enough but also ambivalent about emergency situation. Female dentists have been reported to make decisions more based on 'feeling' (personal values, maintenance of harmony, sympathy and tact) than men, who base decisions more on 'thinking' (logic, consistency, objectivity). ${ }^{13}$ Female dental students have been found to have better social skills, to be more emotionally expressive and sensitive, more verbally expressive and more responsive to patient needs, whereas men have better emotional control. ${ }^{14}$ In addition, male dentists $(46 \%)$ have been perceived as more likely to expect the patient to endure pain compared with female dentists $(8 \%){ }^{15}$ There is also evidence that male and female dentists are more alike than dissimilar. ${ }^{13,16}$ A survey of Canadian dentists revealed that the sexes do not differ in their attitude toward pro bono care, nor in a variety of opinions regarding publicly financed dental care. ${ }^{16} \mathrm{~A}$ US study reported no differences between male and female dentists in the number of treated patients with insurance. ${ }^{17}$

As is known, in dental treatment approach one of the most significant topics is women patients who are in childbearing age. Changes in woman's hormonal milieu have surprisingly strong influence on oral cavity. These changes reflected on tendency to bleed in menstrual cycle, using oral-contraceptive drugs, available drugs during lactation period, and radiographic indications in the risk of pregnancy and reduce of radiation doses. Consequently, all women in the possibility of being pregnant must be asked by dentists before dental treatment. The increased hormonal secretion and the fetal growth induce several systemic, as well as local physiologic and physical changes in a pregnant woman. The main systemic changes occur in the cardiovascular, hematologic, respiratory, renal, gastrointestinal, endocrine, and genitourinary systems. ${ }^{18}$ The local physical changes occur in different parts of the body, which include the dental health. These collective changes may pose various challenges in providing dental care for pregnant patients. Therefore, understanding the physiological changes of the body, the effects of the dental radiation and the medications which are used in dentistry for the pregnant women, lactating mothers and the fetuses, is essential for the management of the pregnant and nursing mothers. ${ }^{19}$ Results of our study showed that female dentists were asking pregnancy risk in more frequency than male dentists, thus shows that women are more sensitive in this condition, or male dentists might be more ashamed than females for talking about pregnancy or associated conditions with female patients. 


\section{CONCLUSION}

According to the results of our study, we found that dentistpatient relationship is strengthened with increasing experience. After dental students become more conscious, they know what to do in emergency situation use simple and clear language and avoid using technical terminology when they contact with patient. Students ensure that the patient has understood what has been said using the patient's own words and giving them a dental meaning. These students' behavior is projection of being experienced. Anamnesis is getting more important with practices of dental students and clinicians. The ability to reflect on the encounter and learning from the experience is an important component in developing self-awareness and professionalism in dentistry. Taking a careful anamnesis and planning treatment stages are success of the dental treatment procedure. In our study, we tried to explain the importance of taking medical history in dentistry and the assessment of knowledge, attitudes and behavior of dentists and dental students.

\section{REFERENCES}

1. Wikipedia, the free encyclopedia. Medical History. Available at: http://en.wikipedia.org/wiki/Medical_history [Date accessed: November 15, 2013]

2. Afşin $H$, Soysal Z, Çağdır S, Gökdoğan M, Altuğ M, Çelik S. Dişhekimliğinde Anamnez. 1st ed. Nobel Tıp Kitabevi, 2006.

3. Abraham-Inpijn L. Internal medicine for dentistry [Inwendige Geneeskunde voor de tandheelkunde]. 2nd ed. Houten [etc.]: Bohn Stafleu Van Loghum, 1993.

4. Veltrini VC, Capelozza ALA, Damante JH. Evaluation of health questionnaires used in dentistry. Special Care in Dentistry 2002; 22(6):221-225.

5. Al Ammar W, Guile E. A one-year survey of dental malpractice claims in Riyadh. Saudi Dent J 2000;12(2):95-99.
6. Attorney Duby C. Have you been hurt by a dentist? Available at: http://connecticutdentalmalpractice.com/[Date accessed: November 15, 2013]

7. Ray AE, Staffa J. The importance of maintaining adequate dental records. NY State Dent J 1993;59(9):55-60.

8. Ireland RS, Harris RV, Pealing R. Clinical record keeping by general dental practitioners piloting the denplan 'Excel' accreditation programme. Brit Dent J 2001;191:260-263.

9. Ptacek JT, Eberhardt TL. Breaking bad news: a review of the literature. JAMA 1996;276:496-502.

10. Lind SE, DelVecchio-Good MJ, Seidel S, Csordas T, Good BJ. Telling the diagnosis of cancer. J Clin Oncol 1989;7:583-589.

11. Conrad DA, Whitney C, Milgrom P, O_Hara D, Ammons R, Fiset W, Vesneski W. Malpractice premiums in 1992: results of a national survey of dentists. J Am Dental Assoc 1995;126: 1045-1056.

12. Doyal L, Cannell $\mathrm{H}$. Informed consent and the practice of good dentistry. Br Dental J 1995;178(12):454-460.

13. Morris DO. Personality types of dental school applicants. Eur J Dent Educ 2000;4(3):100-107.

14. Hannah A, Lim BT, Ayers KM. Emotional intelligence and clinical interview performance of dental students. J Dent Educ 2009;73(9):1107-1117.

15. Smith MK, Dundes L. The implications of gender stereotypes for the dentist-patient relationship. J Dent Educ 2008;72(5):562-570

16. Quinonez CR, Figueiredo R, Locker D. Canadian dentists' opinions on publicly financed dental care. J Public Health Dent 2009;69(2):64-73.

17. Riley JL 3rd, Gordan VV, Rouisse KM, McClelland J, Gilbert GH. Dental practice-based research network collaborative group. Differences in male and female dentists' practice patterns regarding diagnosis and treatment of dental caries: findings from the dental practice-based research network. J Am Dent Assoc 2011;142(4):429-440.

18. Hemalatha VT, Manigandan T, Sarumathi T, Aarthi Nisha V, Amudhan A. Dental considerations in pregnancy: a critical review on the oral care. J Clin Diagn Res 2013;7(5):948-953.

19. Suresh L, Lida R. Pregnancy and lactation. Oral Surg Oral Med Oral Pathol Oral Radiol Endod 2004;97(6):672-682. 